\title{
The communication of dynamics between musicians and listeners through musical performance
}

\author{
TOSHIE NAKAMURA \\ Osaka University, Toyonaka, Osaka, Japan
}

\begin{abstract}
Musicians perform music according to their own interpretations. How does a player realize his/her interpretation of a piece of music in the form of tones? How is his/her intention understood by a listener? In this study, the relationships among the following were investigated quantitatively: (1) the dynamics of a piece of music that professional performers intend to convey to listeners; (2) the intensity of tones produced by the performers; and (3) the listeners' perception of the dynamics of performances, as examined in the listening experiment. Several findings were obtained. (1) In general, performers' intentions were communicated fairly well. (2) When the performers intended to produce a crescendo and intensity was gradually increased, most listeners successfully recognized the crescendo. (3) It appeared that rising pitch enhanced an impression of crescendo, and falling pitch enhanced that of decrescendo. (4) Crescendo was easier both to play and to recognize than was decrescendo. (5) The performer's intention of observing dynamics marks (e.g., $f$ and $p$ ) was conveyed to listeners fairly well, even though the marks did not correspond to a fixed-intensity level. This suggested a context effect common to playing and listening.
\end{abstract}

A piece of music is generally composed by a composer, transformed into a sequence of tones by a performer, and then appreciated by a listener. How is the communication between composer, performer, and listener achieved? Notation of musical compositions is a conventional visual representation of auditory entities: the sounds a composer intends a performer to produce and an audience to hear. The loudness of a tone or a group of tones, the height of the tone, and the temporal aspects of the tone are indicated in a score. The indications in a score, however, are not exact, but only very approximate. The performer decides the exact loudness and height and the parameters of the temporal aspects. Traditional notation leaves room for interpretation on the part of the performer. In practice, very considerable differences are found among performances of the same piece of music. In previous studies, the present author and her colleagues tried to analyze Chopin's Nocturne op. 9, no. 2, Waltz op. 64, no. 1, and Polonaise op. 53 as played by five pianists, and found that there were remarkable differences among the performances by the different players, but that the first and the second performance of the same part of a piece (refrain) by each player was consistent (Nakamura et al., 1979; Namba, Nakamura, \& Kuwano, 1977).

Musicians perform music according to their own interpretations, and it is uncertain whether their intentions are easily understood by the listeners. How does the profes-

The author would like to express her grateful acknowledgment to Seiichiro Namba for valuable discussion, to Mitsuo Yoshida for statistical advice, and to Yoshitaka Nakajima for assistance with the experiment. Requests for reprints should be sent to T. Nakamura, Department of Psychology, College of General Education, Osaka University, Machikaneyama-cho, Toyonaka, Osaka 560, Japan. sional player realize his/her interpretation of a piece of music in the form of tones? What does the audience perceive?

It is important for this study to establish quantitative details of the physical parameters of musical performances that are created between player and listener. The necessary electronic techniques for measuring sound have been developed. This technological advance has enabled us to record music performance visually, and the physical parameters of musical stimuli can in many cases be specified numerically. For example, the author and her colleagues have analyzed musical performances, with respect to the dynamic and temporal aspects of the tones, by using a level recorder (Nakamura et al., 1979; Namba et al., 1977). A level recorder gives a permanent and detailed record of variation of intensity with time. In this paper, the level recorder is also used to analyze the physical aspects of musical performances.

Musical communication can be classified into two categories: (1) the acoustical properties of a musical sound, and (2) the images and ideas that a performance may evoke. This paper is concerned with the first category, and furthermore, confines itself to only one aspect of it: dynamic variation. A consideration of the evoked images and ideas, the second category, was contained in the present author's article on program music (Nakamura, 1983).

In the first stage of my working plan, a professional musician is asked to play a piece of music according to his own interpretation and then to give an outline of his interpretation - of what he is trying to convey to a listener. In the second stage, the dynamic structure of the realized musical stimuli is analyzed physically. From this information, an attempt is made to examine what the performer 
intended to communicate to the listener and how his intention is expressed in terms of dynamics. In the third stage, the listener's perceptual grasp of the performance is examined in specially designed listening experiments. On the basis of the data obtained by these methods, it is hoped that the relationships among performer, sound, and listener can be described.

\section{METHOD}

\section{Stimuli}

The music used in this study was the first and second movements of Sonata in $\mathrm{G}$ major by Willem de Fesch. This baroque music was chosen because it is not popular and there is little information about expression, in terms of notation, provided by the composer.

The material used in the experiment was executed by three professional musicians, members of the Telemann Ensemble, who were well-practiced in playing the piece. They performed on their respective instruments: violin, recorder, and oboe. First, each solo performance was recorded on tape in the musicians' training hall, using a microphone (Aurex 520), located $1 \mathrm{~m}$ from the instrument, and a tape recorder (TEAC 7400). Next, each player was asked to note his own interpretation on the score of the piece. The following instructions were given: "Please note the interpretation you had for the piece when you performed it just now, by means of expression symbols ( $p, f$, cres., dim., accel., rit., etc.)." As an example, the score of the oboe player is given in Figure 1.

\section{Physical Measurement of the Performances}

A level recorder (Brüel \& Kjær 2305) and a filter (Brüel \& Kjær 2120) were used for acoustical measurement of the performances. The decibel level is illustrated in Figure 2 as a function of time. The bar numbers are indicated below each tracing. The intensity level the performer assigned each note can be measured on the recording. The records were obtained using a level recorder with a pen speed of $250 \mathrm{~dB} / \mathrm{sec}$ and a D-weighted $500-\mathrm{Hz}$ high-pass filter; Figure 3 shows the weighting of the filter. Although it is very difficult to determine the best recording method for the quantitative evaluation of a musical performance, the method used here to register intensity and time numerically appeared to correspond to listening perception better than any of the other methods that were tried.

\section{Procedure in the Listening Experiment}

The response sheets (scores) with lists of dynamic symbols on them were placed before the subjects at the start of the experiment. Figure 4, which shows part of the response sheet for the oboe, is an example. The dynamic symbols that could be chosen were located near the parts of the music that had shown strong characteristics in the physical measurements of the performance and in the notations of subjects in a preliminary experiment. (In that experiment, 56 subjects, while listening repeatedly to the performance, had noted their impressions on a score that was without symbols; for this task, they were free to use either musical symbols or words-Nakamura \& Namba, 1982.) In the present experiment, there were separate response sheets for the violin, recorder, and oboe performances. The subjects were required to choose one of the given possible dynamic symbols or to use their own words, as they considered appropriate, to indicate their own impressions of the performance while listening to it. They were told to listen repeatedly, as many times as they needed to make the judgment. Each stimulus was presented at a comfortable level (about $75 \mathrm{dBA}$ ) to all subjects at the same time by means of a loudspeaker in the music classroom that had enough space for 60 students. The order of presentation was: recorder, violin, and then oboe.

\section{Subjects}

Thirty-eight undergraduate and postgraduate students of music participated in the experiment. After the experiment, each subject completed a short questionnaire describing his or her musical training and experience. They had all taken formal lessons in some musical instrument(s) or in singing for many years. None of the subjects had heard this piece before.

\section{RESULTS AND DISCUSSION}

\section{Relationship Between Performer's Intention, Dynamics, and Listeners' Perception}

Crescendo and decrescendo. Table 1 presents the results of the experiment: The intention of the performer, the number of the movement and bar, the amount of increase or decrease in intensity realized in the performance (the difference between the intensity level at the starting note and that at the ending note, corresponding with the $<$ or $>$ marked by a performer), subjects' responses (the percentages for 38 subjects), and the pitch pattern. As shown in Table 1a, the intensity-increments at crescendos marked by the performer in II-4, II-8, II-23, II-6, and I-3 were all more than $9 \mathrm{~dB}$, and most of the subjects $(100 \%, 100 \%, 97.4 \%, 97.4 \%$, and $86.8 \%$, respectively) perceived the crescendo. On the other hand, only $34.2 \%$ of the subjects perceived the crescendo in I-6, where increment in intensity was only $2 \mathrm{~dB}$, although the violinist intended crescendo. It should be noted that if the subjects had only guessed or randomly distributed their judgments over three categories, this would have resulted in about $33 \%$ for each category. With respect to decrescendo, there were too few samples to draw a conclusion. Intensity did not decrease, and thus only $34.2 \%$ of all subjects responded decrescendo. On the basis of these response percentages, it appears that the intention of a performer was communicated well to the listeners, insofar as intensity expressed his intention. Although the above comments are for the violin, the results for the other instruments (the recorder and the oboe) showed the same tendency (see Tables $1 b$ and $1 c$ ).

In addition, it should be noted that rising pitch enhanced the impression of crescendo and that falling pitch enhanced the impression of decrescendo. Even when there was no tendency to increase in intensity, rising pitch caused the impression of crescendo in more than half of the subjects, for example in I-1 in the case of the violin (Table 1a). For the recorder performance, $79 \%$ of subjects responded crescendo although there was no intensity change in II-4 where the pitch pattern was rising. In the case of the oboe, the increase in intensity was larger in I-7 than in II-14, but fewer subjects responded crescendo for the former (falling-pitch pattern) than for the latter.

Also noteworthy is the fact that the performer's intention was conveyed rather well to the listeners in the last part of the piece, even though the performer's interpretation was not embodied in a physical value of the per- 

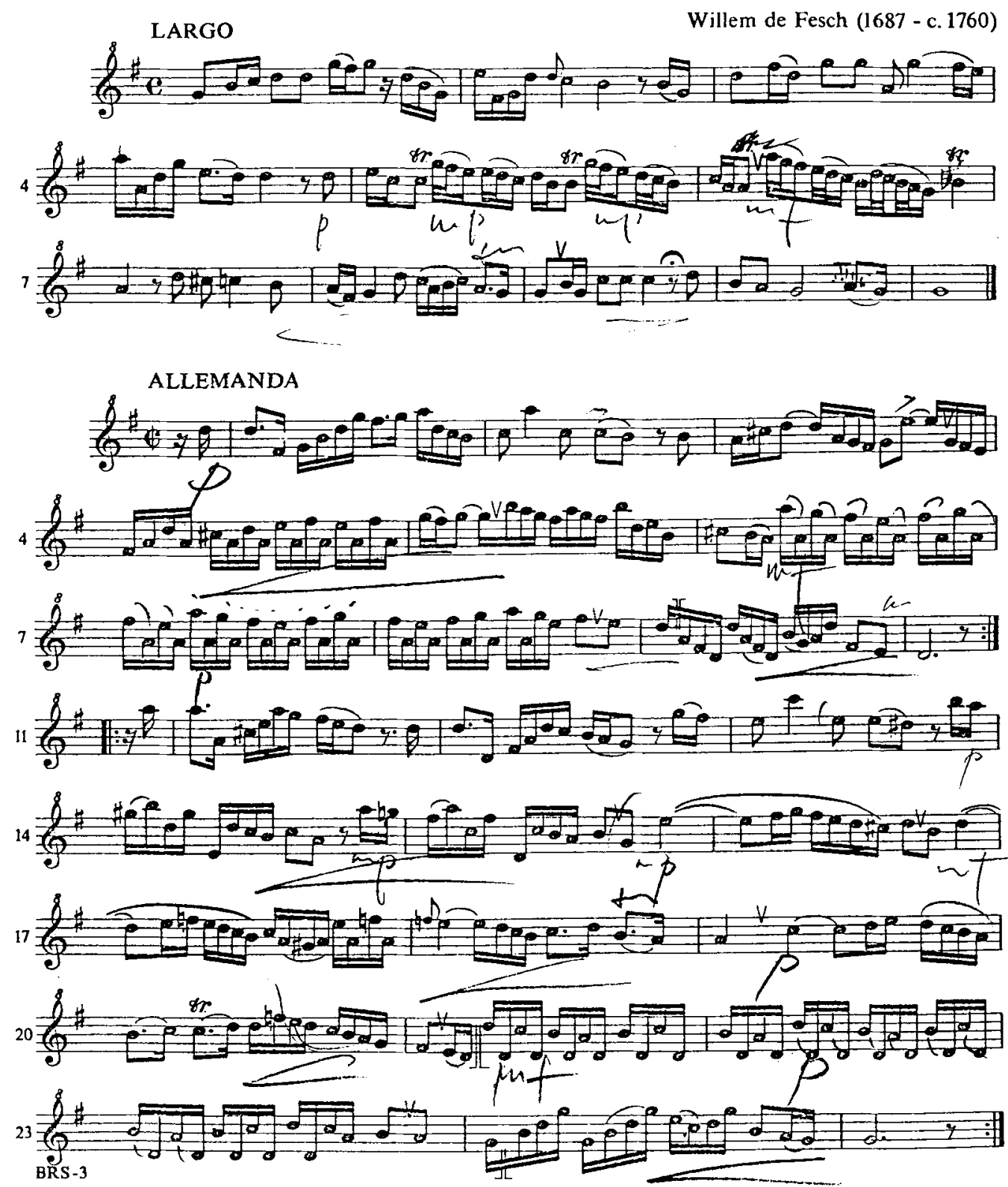

Figure 1. Notation of the music used in the investigation. The hand-written symbols were made by the oboe player to reflect his intentions in its performance. (Copyright 1962 by Hargail Music Press, New York. Reprinted by permission.)

formance. In the performance of II- 24 by the oboist, there was no increase in physical value, but $94.7 \%$ of subjects perceived a crescendo, as the performer intended. Even an 8-dB decrease by the violinist produced an impression of crescendo in $29.0 \%$ of the subjects, and only $2.6 \%$ of the subjects reported decrescendo. It is natural for sound to fade out at the end of a piece. A listener would be listen- ing with such an expectation, so that when the last part of a piece does not fade out as much as expected, an impression of crescendo could be produced in a listener. The possibility of this interpretation was suggested by the present author's experiment (Nakamura, 1986) showing the relationship between crescendo and "impression of the end." 

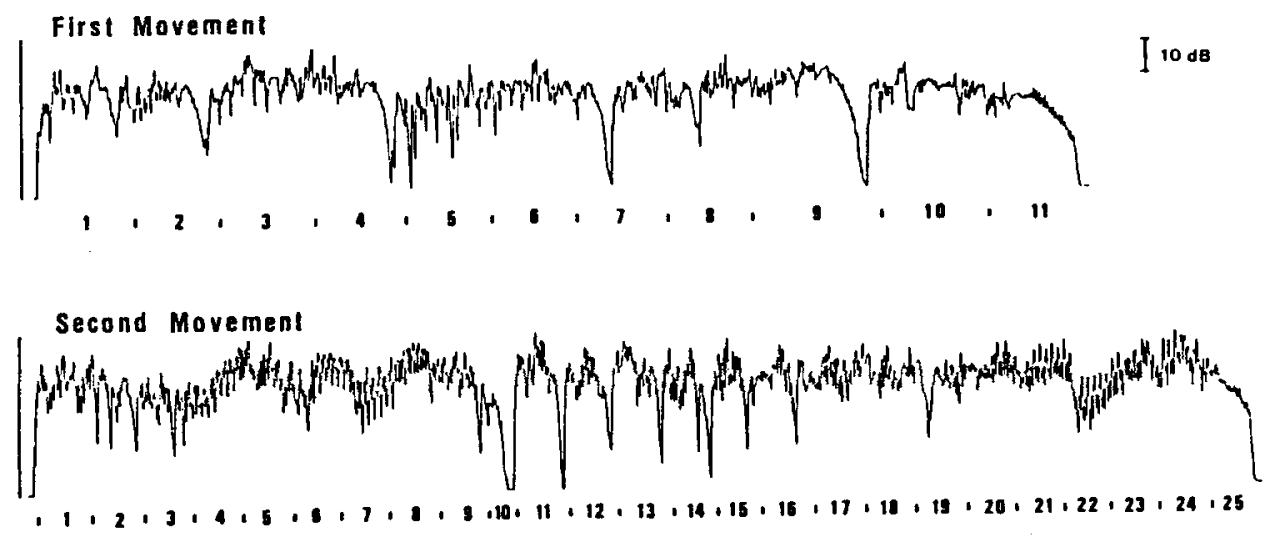

a. Violin
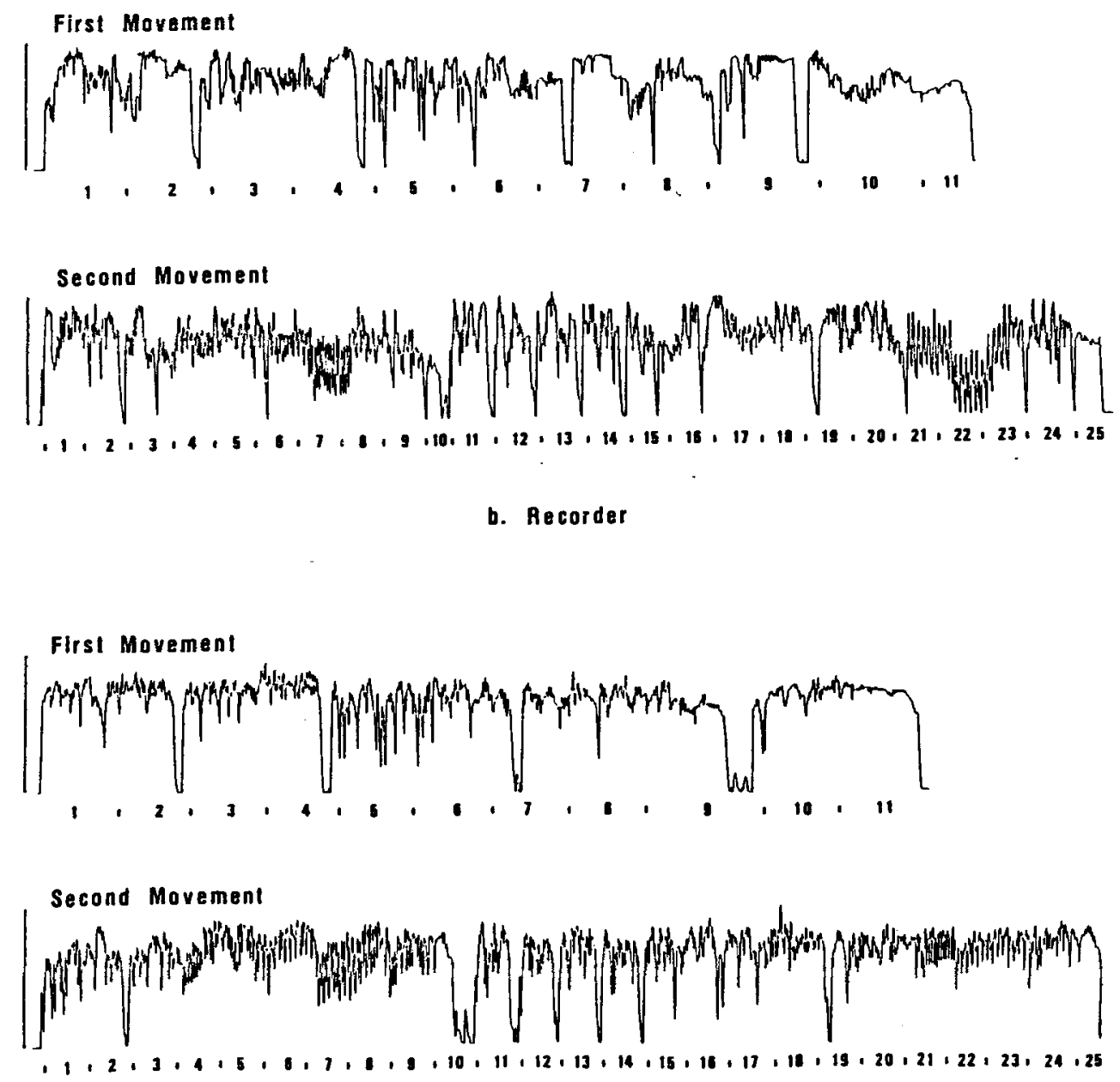

c. Oboe

Figure 2. Intensity changes of the performance as a function of time (a reduced drawing). Bar numbers are given below each intensity tracing. 


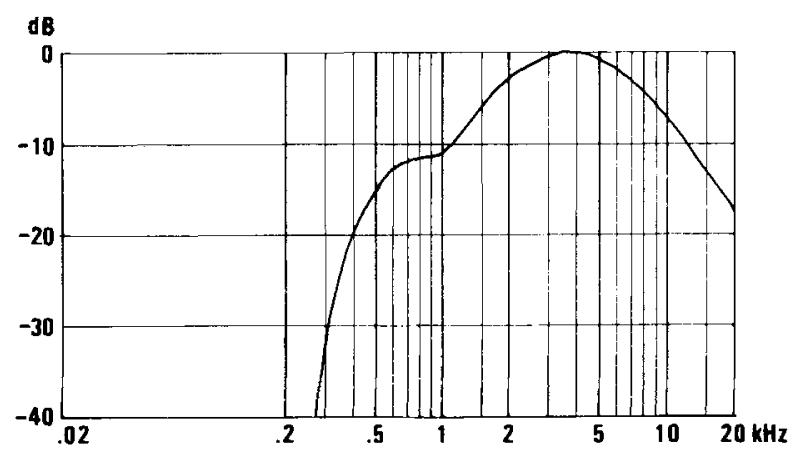

Figure 3. Characteristics of the filter used in measuring the musical performance (D-weighted $500-\mathrm{Hz}$ high-pass filter).
Many factors other than intensity and pitch could also affect perceived crescendo and decrescendo, including, especially, time aspects in performance. No data for discussion of these factors, however, could be obtained from the present analysis.

Dominance of crescendo. Table 2 presents the relationships between intensity changes in the performance and in the subjects' perceptions, as based on all responses indicating crescendo or decrescendo. In the case of increasing intensity, most of the subjective judgments were crescendo for the violin, the recorder, and the oboe $(75.8 \%, 90.4 \%$, and $76.3 \%$, respectively). On the other hand, there were fewer responses of decrescendo for decreasing intensity: the percentages are $53.6 \%$ (violin),

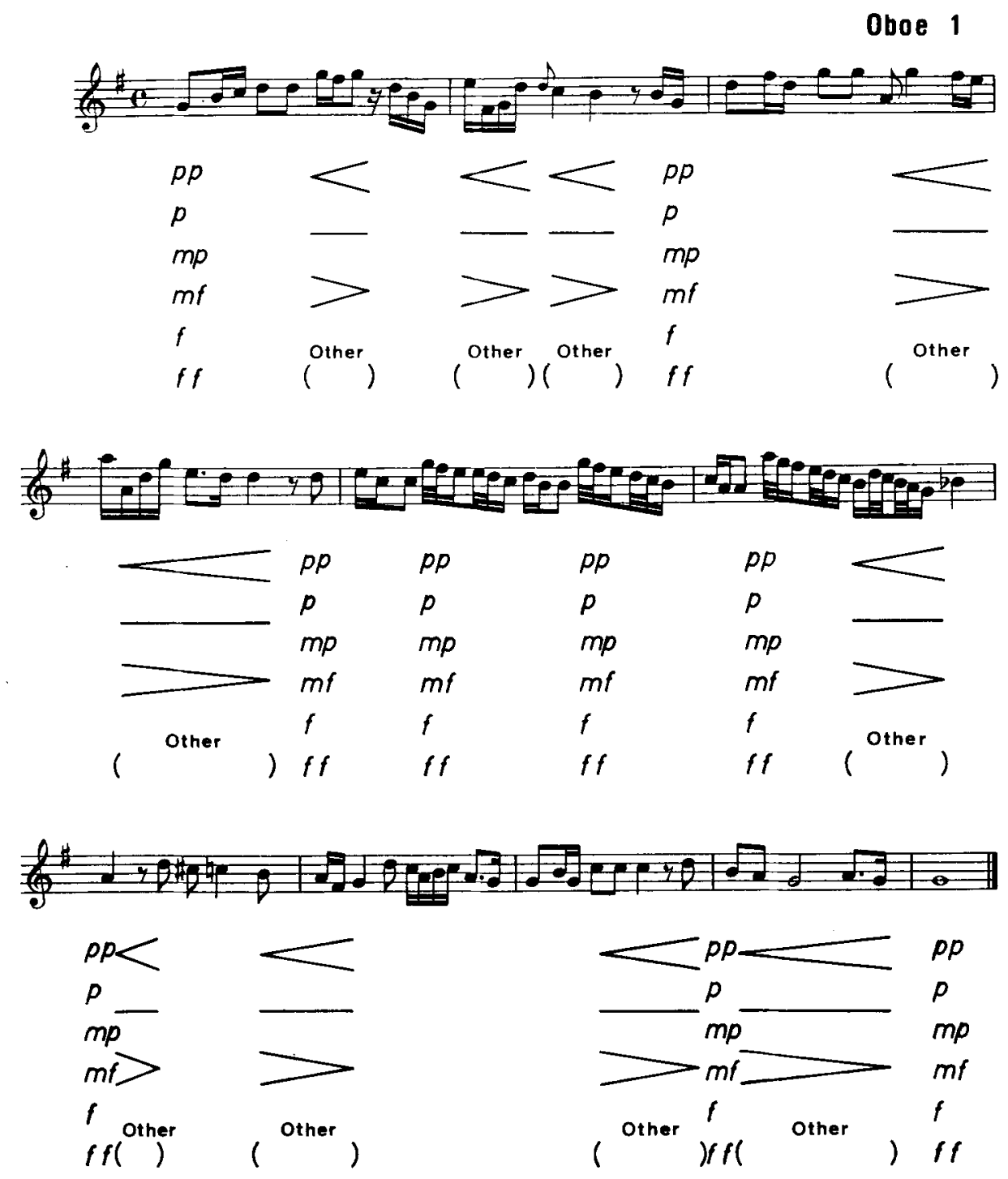

Figure 4. Example of the response sheet used in the listening experiment. 
Table 1

Relationships Among Performer's Intention, Dynamics, and Listeners' Perceptions

\begin{tabular}{|c|c|c|c|c|c|c|}
\hline \multirow{2}{*}{$\begin{array}{l}\text { Performer's } \\
\text { Intention }\end{array}$} & \multirow{2}{*}{$\begin{array}{l}\text { Number of } \\
\text { Movement } \\
\text { and Bar }\end{array}$} & \multirow{2}{*}{$\begin{array}{c}\text { Amount of } \\
\text { Intensity Change }\end{array}$} & \multicolumn{3}{|c|}{$\begin{array}{c}\text { Listeners' Responses } \\
\text { (Percentage of } 38 \text { Subjects) }\end{array}$} & \multirow{2}{*}{$\begin{array}{l}\text { Pitch } \\
\text { Pattern }\end{array}$} \\
\hline & & & $<$ & 二 & $>$ & \\
\hline \multicolumn{7}{|c|}{ a. Violin } \\
\hline & II-4 & $14 \mathrm{~dB}$ Increase & 100.0 & 0.0 & 0.0 & Rising \\
\hline & II-8 & $10 \mathrm{~dB}$ Increase & 100.0 & 0.0 & 0.0 & Rising \\
\hline & II-23 & $10 \mathrm{~dB}$ Increase & 97.4 & 2.6 & 0.0 & Rising \\
\hline & II-6 & $10 \mathrm{~dB}$ Increase & 97.4 & 0.0 & 2.6 & Rising \\
\hline & $\mathrm{I}-3$ & $9 \mathrm{~dB}$ Increase & 86.8 & 13.2 & 0.0 & Falling \\
\hline & I-6 & $2 \mathrm{~dB}$ Increase & 34.2 & 57.9 & 5.3 & Falling \\
\hline & I-1 & No Increase & 63.2 & 36.8 & 0.0 & Rising \\
\hline & III-24 & $8 \mathrm{~dB}$ Decrease & 29.0 & 60.5 & 2.6 & (Last) \\
\hline & $\mathrm{I}-2$ & No Decrease & 13.2 & 36.8 & 34.2 & Falling \\
\hline \multicolumn{7}{|c|}{ b. Recorder } \\
\hline & III-8 & $14 \mathrm{~dB}$ Increase & 100.0 & 0.0 & 0.0 & Rising \\
\hline & I-3 & $14 \mathrm{~dB}$ Increase & 92.1 & 5.3 & 2.6 & Same \\
\hline & II-23 & $9 \mathrm{~dB}$ Increase & 86.8 & 13.2 & 0.0 & Rising \\
\hline & $\mathrm{I}-1$ & $1 \mathrm{~dB}$ Increase & 71.1 & 26.3 & 0.0 & Same \\
\hline & $\mathrm{II}-4$ & No Increase & 79.0 & 21.0 & 0.0 & Rising \\
\hline & $I-6$ & 14 dB Decrease & 10.5 & 47.4 & 42.1 & Falling \\
\hline & $\mathrm{I}-2$ & No Decrease & 42.1 & 50.0 & 7.9 & - \\
\hline \multicolumn{7}{|c|}{ c. Oboe } \\
\hline & II-4 & $16 \mathrm{~dB}$ Increase & 97.4 & 0.0 & 0.0 & Rising \\
\hline & III-18 & $13 \mathrm{~dB}$ Increase & 89.5 & 10.5 & 0.0 & - \\
\hline & I-7 & $9 \mathrm{~dB}$ Increase & 55.3 & 36.8 & 5.3 & Falling \\
\hline & III-14 & $4 \mathrm{~dB}$ Increase & 71.1 & 23.7 & 2.6 & - \\
\hline & II-24 & No Increase & 94.7 & 5.3 & 0.0 & (Last) \\
\hline & II-9 & No Increase & 47.4 & 39.5 & 13.1 & - \\
\hline & II-20 & No Increase & 34.2 & 55.3 & 7.9 & Falling \\
\hline & II-8 & $9 \mathrm{~dB}$ Decrease & 18.4 & 42.1 & 39.5 & Falling \\
\hline- & $=I-9$ & $12 \mathrm{~dB}$ Decrease & 5.2 & 63.2 & 31.6 & - \\
\hline
\end{tabular}

Note-In some cases, the total of the percentages is less than 100 percent due to no answers.

$37.6 \%$ (recorder), and $27.0 \%$ (oboe). It could be concluded that crescendo was easier to recognize and decrescendo more difficult. This tendency is easily seen in the responses for the parts where intensity did not tend to change in any particular direction. Although there was no increase in intensity, about half of all the responses for these parts were crescendo: $39.5 \%$ (violin), $55.3 \%$ (recorder), and $57.1 \%$ (oboe); responses for the opposite case, decrescendo, were very much fewer $(19.7 \%$, $10.0 \%$, and $11.7 \%$, respectively). Moreover, other research (Nakamura, 1980, 1982), using artificial steadystate tones, has supported this observation, that is, that crescendo was easier to recognize than decrescendo. In view of this, it may be said that decrescendo is difficult in two respects-in its expression and in its appreciation. The first is the difficulty of transforming the player's intended decrescendo into a sequence of tones in such a way that intensity gradually decreases with time in playing; the second is the apparent failure of a listener to recognize the diminution in intensity.

\section{$p$ and $f$ as Intended and as Realized by the \\ Performer and as Perceived by the Listener}

Each performer intended in some places to give expression to the notations $p$ and $f$. To what extent were these intentions communicated to the listeners? Table 3 shows the relationship between the performer's intention and the tener's perception for each instrument. Many of the responses did not correspond with the symbol that signified the performer's intention, although the $p$ responses that corresponded to the violinist's intention amounted to $52.6 \%$ of all responses, which was higher than any other responses ( $p p, m p, m f, f$, and $f f$ ). The same was true of $f$ for the violin $(38.2 \%), p$ for the recorder $(45.4 \%), m p$ for the oboe (44.7\%), and $m f$ for the oboe (42.8\%). However, since the responses were not to live music but to recorded tape, the impressions of the listeners might be dependent on the playback-level in the experiment. Therefore, it seems more important to examine whether a listener's impression of loudness changed consistently with a performer's intention-that is, whether there was agreement between the performer's intention of producing a louder sound and the listener's perception of a louder sound, rather than simply agreement on the specific marking symbol.

For this purpose, Goodman-Kruskal's rank measure of association (Index $\gamma$-Goodman \& Kruskal, 1954, 1963) was calculated to examine the degree of concordance between two variables. Calculated values were $G=.808$ (violin, $n$ [number of responses] $=\mathbf{2 2 8}, \mathbf{9 5 \%}$ confidence 
interval: $.703 \leq \gamma \leq .914$ ),$G=.811$ (recorder, $n=494, .758 \leq \gamma \leq .863$ ), and $G=.472$ (oboe, $n=532, .378 \leq \gamma \leq .566$ ). Since the possible value of $G$ is from -1 to 1 , it can be concluded that listeners' impressions very closely corresponded to the performers' intentions for the violin and recorder, and fairly closely so for the oboe. In other words, the performer's intention was communicated rather well to the listeners.

Next, we examine the relationship between the dynamic symbols marked by the performer and the intensity realized by him. As is shown in Figure 5, the intensity levels for each symbol varied considerably depending on place in the score, although their average values increased or decreased according to the mean of the symbols. This finding agrees with that of previous research by the present author (Nakamura et al., 1979; Namba et al., 1977). As those studies suggested, it is to be expected that intensity level is not fixed by a given dynamic symbol, but is influenced by context. It is to be expected also that this effect would appear in the listener's perception. GoodmanKruskal's rank measure of association was calculated in order to examine the relationship between physical values and the listener's judgment. The values were $G=.669$
Table 2

Relationship Between Intensity Changes in Performance and Listeners' Perceptions

\begin{tabular}{|c|c|c|c|}
\hline \multirow{2}{*}{$\begin{array}{l}\text { Listeners' } \\
\text { Judgment }\end{array}$} & \multicolumn{3}{|c|}{ Intensity Change in Performance } \\
\hline & Increasing & Constant & Decreasing \\
\hline \multicolumn{4}{|c|}{ a. Violin } \\
\hline 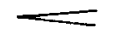 & $461(75.8 \%)$ & $60(39.5 \%)$ & $45(10.7 \%)$ \\
\hline & $113(18.6 \%)$ & $55(36.2 \%)$ & $137(32.8 \%)$ \\
\hline$\Longrightarrow$ & $21(3.5 \%)$ & $30(19.7 \%)$ & $224(53.6 \%)$ \\
\hline Other & $13(2.1 \%)$ & $7(4.6 \%)$ & $12(2.9 \%)$ \\
\hline Total & $608(100 \%)$ & $152(100 \%)$ & $418(100 \%)$ \\
\hline & \multicolumn{2}{|c|}{ b. Recorder } & \\
\hline$\simeq$ & $309(90.4 \%)$ & $105(55.3 \%)$ & $92(24.2 \%)$ \\
\hline & $23(6.7 \%)$ & $63(33.1 \%)$ & $142(37.4 \%)$ \\
\hline$=$ & $8(2.3 \%)$ & $19(10.0 \%)$ & $143(37.6 \%)$ \\
\hline Other & $2(0.6 \%)$ & $3(1.6 \%)$ & $3(0.8 \%)$ \\
\hline Total & $342(100 \%)$ & $190(100 \%)$ & $380(100 \%)$ \\
\hline \multicolumn{4}{|c|}{ c. Oboe } \\
\hline & $290(76.3 \%)$ & $152(57.1 \%)$ & $89(29.3 \%)$ \\
\hline & $75(19.7 \%)$ & $81(30.5 \%)$ & $127(41.8 \%)$ \\
\hline$=$ & $9(2.4 \%)$ & $31(11.7 \%)$ & $82(27.0 \%)$ \\
\hline Other & $6(1.6 \%)$ & $2(0.7 \%)$ & $6(1.9 \%)$ \\
\hline Total & $380(100 \%)$ & $266(100 \%)$ & $304(100 \%)$ \\
\hline
\end{tabular}

Table 3

Relationship Between Dynamic Symbols Written by Performer and Listeners' Perceptions

\begin{tabular}{crrr}
\hline Listeners' & \multicolumn{3}{c}{ Performer's Intention } \\
\cline { 2 - 4 } Judgment & \multicolumn{1}{c}{$p$} & $m p$ & \multicolumn{1}{c}{$f$} \\
\hline & & a. Violin & \\
$p p$ & $7(4.6 \%)$ & & $1(1.3 \%)$ \\
$p$ & $80(52.6 \%)$ & & $9(11.8 \%)$ \\
$m p$ & $55(36.2 \%)$ & & $21(27.6 \%)$ \\
$m f$ & $9(5.9 \%)$ & & $13(17.1 \%)$ \\
$f$ & $0(0.0 \%)$ & & $29(38.2 \%)$ \\
$f f$ & $0(0.0 \%)$ & & $3(3.9 \%)$ \\
No Answer & $1(0.7 \%)$ & & $0.0 \%)$ \\
Total & $152(100 \%)$ & & $76(100 \%)$
\end{tabular}

$\begin{array}{cr}p p & 21(13.8 \%) \\ p & 69(45.4 \%) \\ m p & 52(34.2 \%) \\ m f & 7(4.6 \%) \\ f & 0(0.0 \%) \\ f f & 0(0.0 \%) \\ \text { No Answer } & 3(2.0 \%) \\ \text { Total } & 152(100 \%)\end{array}$

\begin{tabular}{cr}
$p p$ & $18(7.9 \%)$ \\
$p$ & $73(32.0 \%)$ \\
$m p$ & $97(42.5 \%)$ \\
$m f$ & $37(16.2 \%)$ \\
$f$ & $2(0.9 \%)$ \\
$f f$ & $0(0.0 \%)$ \\
No Answer & $1(0.4 \%)$ \\
Total & $228(100 \%)$ \\
\hline
\end{tabular}

b. Recorder

$\begin{array}{rr}10(13.2 \%) & 1(0.4 \%) \\ 26(34.2 \%) & 13(4.9 \%) \\ 36(47.4 \%) & 88(33.1 \%) \\ 2(2.6 \%) & 120(45.1 \%) \\ 0(0.0 \%) & 42(15.8 \%) \\ 0(0.0 \%) & 1(0.4 \%) \\ 2(2.6 \%) & 1(0.4 \%) \\ 76(100 \%) & 266(100 \%)\end{array}$

$\begin{array}{rr}\text { c. Oboe } & \\ 6(3.9 \%) & 0(0.0 \%) \\ 64(42.1 \%) & 10(6.6 \%) \\ 68(44.7 \%) & 50(32.9 \%) \\ 9(5.9 \%) & 65(42.8 \%) \\ 0(0.0 \%) & 25(16.4 \%) \\ 0(0.0 \%) & 1(0.7 \%) \\ 5(3.3 \%) & 1(0.7 \%) \\ 52(100 \%) & 152(100 \%)\end{array}$

Note-The data indicate the number and percentages of subject judgments that agreed with the performer's intentions as indicated by his use of dynamic symbols. $p p=$ pianissimo (very soft), $p=$ piano (soft), $m p=$ mezzopiano (moderately soft), $m f=$ mezzoforte (moderately loud), $f$ $=$ forte (loud), and $f f=$ fortissimo (very loud). 


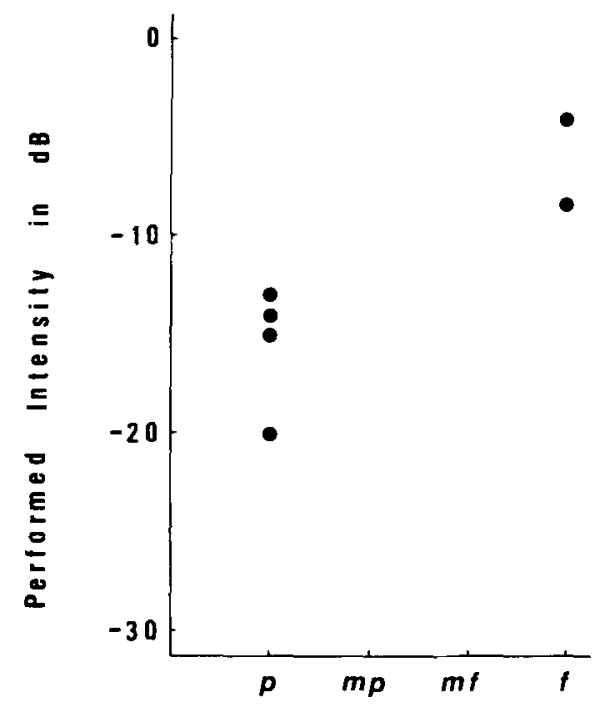

a. Violin

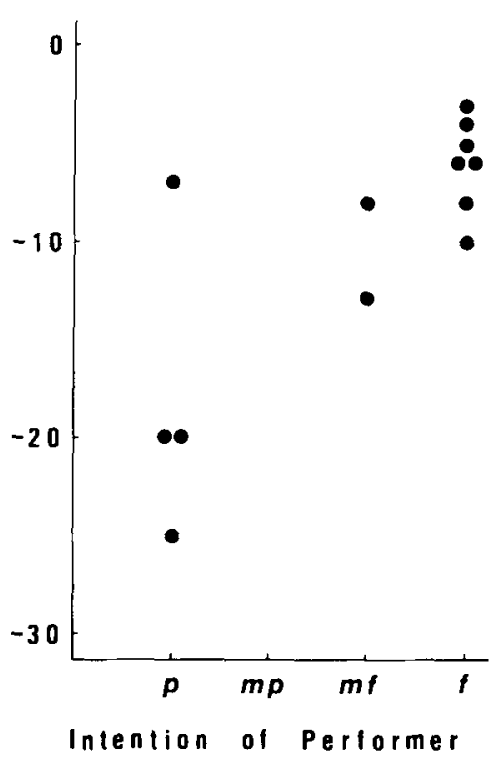

b. Recorder

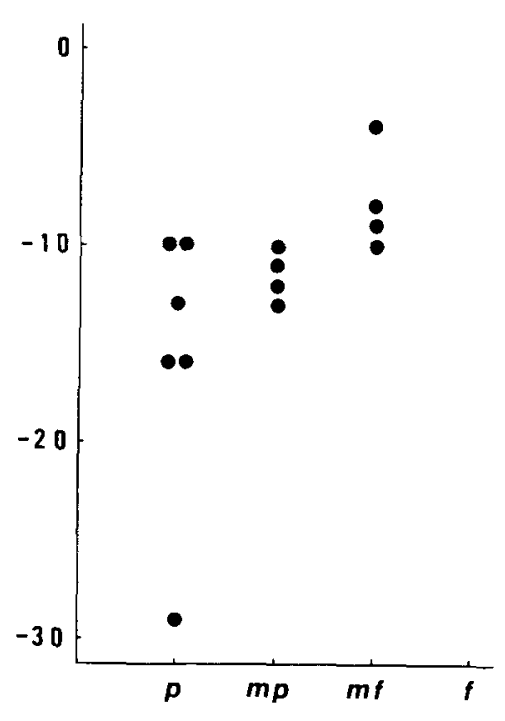

c. 0 bo e

Figure 5. Relationship between the dynamic mark indicating the intention of the performer and intensity of tone as realized (in decibels relative to maximum intensity in the performance).

for violin $(n=676, .629 \leq \gamma \leq .709), G=.307$ for recorder $(n=714, .235 \leq \gamma \leq .379)$, and $G=.264$, for oboe $(n=1008, .210 \leq \gamma \leq .318)$. There is only a slight association in the case of the recorder or oboe, but a fairly good association in the case of the violin. This suggests that the listeners' impressions were not determined entirely by the absolute value of physical intensity, but were influenced by context. In the case of the oboe, for example, the realized intensity for $p$ in I-4 and $m f$ in II-21 was physically the same $(-10 \mathrm{~dB}$, as shown in Figure 5). At the same time, the listeners' impressions of loudness were clearly different for these parts, with the former being perceived as softer than the latter (with the former, $92 \%$ of all responses were concentrated in $p$ and $m p$; with the latter $92 \%$ were concentrated in $m f$ and $f$ ). This is probably because the preceding intensity was louder for the former and softer for the latter. It seems that the rather good communication of $p$ and $f$ between performers and listeners, in spite of discordance in the physical dimension, can be attributed partly, at least, to a context effect as a perceptual characteristic that is common to playing and listening.

\section{CONCLUSION}

The result shows that, in general, the performers' intention could be communicated to the listeners fairly well. With regard to crescendo and decrescendo, the first requisite of good communication between a performer and a listener seemed to be that the intensity of a tone sequence executed by the performer varied in accordance with his intention. When the performer intended to produce a crescendo, and the intensity increased sufficiently and gradually, for instance, most listeners successfully recog- nized the crescendo. Furthermore, it appears that crescendo was easier, both for playing and for recognizing, than decrescendo. Among the other factors, an effect of pitch pattern on perceived crescendo and decrescendo was found.

In the case of other dynamic marks ( $p$ and $f$ ), however, discordance between the dynamic mark and intensity of tones did not result in poor communication between the performer and the listener. Unlike crescendo and decrescendo, where the crucial matter is the manner of the intensity change of tones in a certain context, the " $a b$ solute" levels of $p$ and $f$ at different places in the score can vary considerably, depending on the specific musical context. Although, from the present data, this effect could not be examined in detail, it can be assumed to be one of the reasons why there was good communication between the performers and the listeners despite the fact that the physical values did not correspond to dynamic symbols.

There are not many published papers that provide empirical data on communication between performer and listener, although many suggestions appear in research (Clarke, 1985; Gabrielsson, 1982, 1985; Gabrielsson, Bengtsson, \& Gabrielsson, 1983; Harvey, 1985; Mori, Suga, \& Taguti, 1987; Nakajima \& Nishimura, 1986; Patterson, 1974; Rasch, 1979; Sasaki, Ishikawa, \& Yamada, 1986; Shaffer, 1981; Sloboda, 1982, 1983, 1985; Sundburg, Askenfelt, \& Frydén, 1983; Takahashi, 1984). As Gabrielsson (1985) puts it, investigations of the relationships between performance and listeners' experience are just beginning.

Communication between performer and listener involves various factors, and the sound sequences produced by music performers aie very complex. The present 
author has concentrated on one of the acoustical factorsintensity - and has ventured to explore the relationship between performer, physical properties, and listener perception. On the basis of the results of this study, the author has undertaken several further experiments, using synthesized sound sequences under well-controlled conditions, which generally confirm the interpretations presented in the present article.

\section{REFERENCES}

Clarke, E. F. (1985). Structure and expression in rhythmic performance. In P. Howell, I. Cross, \& R. West (Eds.), Musical structure and cognition (pp. 209-236). London: Academic Press.

Gabrielsson, A. (1982). Perception and performance of musical rhythm. In M. Clynes (Ed.), Music, mind, and brain: The neuropsychology of music (pp. 159-169). New York: Plenum Press.

GABRIELSSON, A. (1985). Interplay between analysis and synthesis in studies of music performance and music experience. Music Perception, 3, 59-86.

Gabrielsson, A., Bengtsson, I., \& Gabrielsson, B. (1983). Performance of musical rhythm in $3 / 4$ and 6/8 meter. Scandinavian Journal of Psychology, 24, 193-213.

Goodman, L. A., \& KrUSKAL, W. H. (1954). Measures of association for cross classifications. Journal of the American Statistical Association, 49, 732-764.

Goodman, L. A., \& Kruskal, W. H. (1963). Measures of association for cross classifications III: Approximate sampling theory. Journal of the American Statistical Association, 58, 310-364.

HARVEY, N. (1985). Vocal control in singing: A cognitive approach. In P. Howell, I. Cross, \& R. West (Eds.), Musical structure and cognition (pp. 287-332). London: Academic Press.

MorI, S., Suga, S., \& TAGUTI, T. (1986). [A psychological study on musical tempo] (in Japanese). Journal of Konan University, Faculty of Letters, 63, 23-38.

Nakajima, Y., \& Nishimura, N. (1986). [On the relationship between the notated time values and the physical durations of the notes in simple rhythm patterns] (in Japanese). (Technical Report of Musical Acoustics, MA-86-13, 16-23). Tokyo: Acoustical Society of Japan.

NAKamura, T. (1980). [Loudness discrimination for sounds whose intensity continuously change with time: A proposal of dynamic difference limen] (in Japanese). Joumal of the Acoustical Society of Japan, 36, 238-243.

NAKAMURA, T. (1982). [The effect of pitch pattern on the recognized crescendo and decrescendol (in Japanese). Reports of the 1982 Spring Meeting of the Acoustical Society of Japan, pp. 215-216.

NakamURA, T. (1983). [Psychological investigations into some aspects of program music and listener attitude/response] (in Japanese). In Studies in the humanities and social sciences (Vol. 31, pp. 25-40). Osaka: Osaka University, College of General Education.

Nakamura, T. (1986). [The measurement of loudness discrimination for sounds whose intensities continuously change with time, by a new method] (in Japanese). Reports of the 1986 Fall Meeting of the Acoustical Society of Japan, pp. 297-298.

Nakamura, T., \& Namba, S. (1982). [The communication between musicians and listeners through musical performancel (in Japanese). In Studies in the Humanities and Social Sciences (Vol. 30, pp. 3-15). Osaka: Osaka University, College of General Education.

Nakamura, T., Namba, S., Yagi, M., Kuwano, S., Kato, T., ISHIBASHI, H., \& SAKURABAYASHI, H. (1979). [On the evaluation of piano performance: The effects of listening attitude] (in Japanese). In Studies in the Humanities and Social Sciences (Vol. 27, pp. 2137). Osaka: Osaka University, College of General Education.

Namba, S., Nakamura, T., \& Kuwano, S. (1977). IAn analysis of piano performance] (in Japanese). In Studies in the Humanities and Social Sciences (Vol. 25, pp. 25-42). Osaka: Osaka University, College of General Education.

Patterson, B. (1974). Musical dynamics. Scientific American, 231, 78-95.

RASCH, R. A. (1979). Synchronization in performed ensemble music. Acustica, 43, 121-131.

SaSAKI, M., IshikaWA, T., \& Yamada, M. (1986). [The comparison between temporal fluctuation of beat in piano performance at the case of free and equal tempo using simple type music sample] (in Japanese). (Technical Reports of Musical Acoustics, MA-86-1, 1-6). Tokyo: Acoustic Society of Japan.

Shaffer, L. H. (1981). Performances of Chopin, Bach, and Bartok: Studies in motor programming. Cognitive Psychology, 13, 326-376.

SLOBoda, J. A. (1982). Music performance. In D. Deutsch (Ed.), The psychology of music (pp. 479-496). New York: Academic Press.

SLOBOdA, J. A. (1983). The communication of musical metre in piano performance. Quarterly Journal of Experimental Psychology, 35A, 377-396.

SLoboda, J. A. (1985). The musical mind: The cognitive psychology of music. New York: Oxford University Press.

Sundberg, J., Askenfelt, A., \& Frydén, L. (1983). Musical performance: A synthesis-by-rule approach. Computer Music Journal, 7, $37-43$.

TAKAHASHI, J. (1984). [Microtone pitch shifts in scale singing-Effects caused by the pronunciation of the vowels " $a$ " and " $i$ "] (in Japanese). In Music research (Vol. 2, pp. 7-22). Osaka: Osaka College of Music. 